Teaching \& Learning (2016/2017), 11(1), 16-31

\title{
Choosing How We Choose: A Review of Teacher Education Admissions Literature
}

\author{
MICHAEL HOLDEN \\ Brock University \\ JULIAN KITCHEN \\ Brock University
}

\begin{abstract}
Regulation 283/13 and the Ontario Ministry of Education's decision to reduce teacher education admission rates by $50 \%$ provide a clear opportunity to reflect on the alignment between admissions practices and the programs that they serve. This article presents an overview of teacher education admissions literature, identifying the many purposes that admissions processes serve, the ways teacher educators may connect purpose to practice, as well as the equity issues inherent to program admissions. The strengths and limitations of seven common assessment tools are also presented. This information will be of interest to stakeholders involved in teacher education, and is intended to support teacher educators in making informed selection and admission decisions for their particular programs.
\end{abstract}

\section{Introduction}

In 2013, the Ontario Ministry of Education (OME) introduced Regulation 283/13, requiring teacher education programs to increase their minimum number of semesters from two to four, and increase the minimum number of field experience days in their programs from 40 to 80 (Kitchen \& Petrarca, 2015). Moreover, the government announced a plan to reduce admission rates to teacher education programs by $50 \%$ to "address an oversupply of graduates, enabling Ontario's qualified teachers to find jobs" (OME, 2013a, para. 4). Thus, in addition to the structural and substantive changes to teacher education, Ontario's teacher education programs also face challenges in adjusting their admissions practices (Thomas \& Kane, 2015).

These challenges must be addressed if admissions practices are to align to the programs they serve. For example, teacher educators must consider which admissions tools to use (Petrarca \& LeSage, 2014), and how those tools will affect the makeup of their student cohorts (Childs et al., 2016). They must consider which requirements are necessary (Falkenberg, 2010), and which policies help them to respond to students' needs as emerging educators (Hirschkorn \& Sears, 2015). As Eva, Rosenfeld, Reiter, and Norman (2004) note, "there is considerable controversy 
regarding how best to select individuals from pools of highly qualified applicants" (p. 314), and in particular, how to select candidates most appropriate for a program's approach (Kitchen \& Petrarca, 2016). This article, based on a larger study of admissions practices in Ontario (Holden, Kitchen, Petrarca, \& LeSage, 2016), aims to support teacher educators by identifying these issues, and by presenting an overview of teacher education admissions literature - particularly in the Canadian context. Teacher educators may then use this information to inform decisions at their own institutions, and develop admissions practices that support their program goals.

\section{The Many Purposes of Admissions Practices}

At their most basic level, admissions practices select which applicants are qualified to enter teacher education programs and which are not (DeLuca, 2012). This gatekeeping function has lasting implications: teacher education programs have low rates of attrition, failure, and withdrawal (Childs \& Ferguson, 2015; Dore et al., 2009; Kosnik, Brown, \& Beck, 2005). As a result, admissions practices are often viewed as the only systematic opportunity to select candidates who are suitable to the program and the profession (Dore et al., 2009). In some cases, the concern for selecting quality applicants is significant. Kosnik and colleagues (2005), for example, found that $15.6 \%$ of applicants admitted to their program were of the poorest quality, and yet almost all of these undesirable candidates completed the program and were certified as teachers.

Beyond their utility as a gatekeeping practice, admissions standards also shape the future of the profession. For the student, admission to a program increases their social capital and positions them as a citizen who will one day shape education for future generations (Guinier, 2003). For the university, admissions may serve as "a public statement of the [institution's] values" (Marrin, McIntosh, Keane, \& Schmuck, 2004, p. 130). As Kosnik and colleagues (2005) note, accepted candidates become ambassadors for the university and its programs, and the quality of their representation affects the perceived quality of the institution. In this sense, admissions practices extend well beyond a simple filter for acceptance into a program.

Admissions practices must also be responsive to a variety of internal and external factors. New practices must be cost effective (Eva et al., 2004) and engage multiple stakeholders to 
generate the buy-in necessary for real change (Petrarca \& LeSage, 2014; Thomas \& Kane, 2015). As Mulholland and Salm (2015) note, without the support of field partners, changes may have limited effects. The challenge of stakeholders becomes increasingly complex when considering how Ontario's teacher education programs are structured (see Crocker \& Dibbon, 2008). Ontario's institutions vary in size and the number of applicants (Kosnik et al., 2005; Childs et al., 2011) and so necessarily, changes which are feasible for one program may not necessarily transfer to another.

Indeed, different institutions identify different purposes for their admissions practices. Crocker and Dibbon's (2008) pan-Canadian study of teacher education programs identified programs that valued social justice, equity, and producing competent, reflective practitioners. Caskey, Peterson, and Temple (2001) similarly highlight giving consideration to applicants' appreciation for multicultural education. Meanwhile, Kosnik and colleagues (2005) describe an admissions process that seeks to identify "strong interpersonal skills, good problem-solving skills, keen reflective tendencies, a broad world-view, and a social conscience" (p. 103). Each of these purposes may alter the way in which the program selects its candidates.

A relatively recent purpose emerging in Canadian teacher education is to design admissions practices that are responsive to the qualities applicants bring to these programs. Hirschkorn and Sears (2015) contend that admissions data should be used not only to determine which candidates are admitted, but also to support student growth within the program. Thomson and colleagues (2011) similarly suggest that admissions practices should consider applicants' journeys as emerging educators. Programs viewing admissions from this perspective may enable their admissions committees to be more flexible when applicants score highly on some criteria but perform poorly on others (Falkenberg, 2010; Hirschkorn \& Sears, 2015). While this purpose for admissions practices is not the norm in Canada, it offers a specific example of how teacher educators can actively choose what their admissions practices will do, and what goals those practices will ultimately support. 


\section{Connecting Purpose to Practice}

In the previous section, we discussed the different purposes of admissions practices. As Denner, Salzman, and Newsome (2001) note, admissions practices should align with program purposes, so that the way candidates are selected supports the goals of the program itself. Thus, in this section, we consider the challenge of connecting program purposes with specific admissions practices. This apparently obvious connection is difficult to implement. While effective teacher education programs often share similar themes (O’Connor, Nickel, \& Sterenberg, 2015), admission committee members sometimes differ in their interpretation of the purpose of admissions practices (DeLuca, 2012). Further, admissions tools are not always linked to frameworks for admission (Denner et al., 2001). These inconsistencies can limit the connection between the intended purpose of admissions practices and what is actually occurring in admissions. Consider, for example, an institution seeking to identify applicants with a desire to teach inclusively. As one participant in DeLuca's (2012) study noted, "no one ever says 'I am a racist homophobic pig' on their [application]. And yet they come here and they are" (p. 20). Despite their desire to select inclusive applicants, DeLuca's teacher educators struggled to design admissions practices that would support their goal.

Petrarca and LeSage (2014) pose a relevant question for linking purpose with practice: "if the ultimate goal of the admission process is to attract and admit candidates who demonstrate potential for becoming effective teachers, how do we know that our admission process achieves this goal" (p. 259)? Thomson and colleagues (2011) offer one possible response. They suggest that teacher educators should develop an "explicit coherence" of the alignment between purpose and practice (p. 2). Casey and Childs (2007) similarly suggest teacher educators should base their admissions practices on clear research and an analysis of their own program's capabilities. Rather than creating a limited consensus on what each criteria means, DeLuca (2012) suggests that teacher educators might develop a conceptual framework that is open to multiple perspectives. For DeLuca (2012), such a response would acknowledge the range of possible interpretations, and allow a program to admit applicants whose philosophies may differ somewhat from the institution's predetermined criteria. Each of these recommendations reflects Casey and Childs' (2011) contention that teacher educators should have clear rationales for their admission practices. 
Another consideration in making admissions practices explicit, relates to the applicants themselves. Caskey and colleagues (2001) contend that applicants should be told, explicitly, what the admissions process involves, and why certain practices are important to the program in question. Thomson and colleagues (2011) similarly suggest that providing applicants with a clear understanding allows them to determine if the program meets their own expectations. Moreover, Childs and colleagues (2011) believe that making admission practices explicit "might reduce the advantage of applicants who are more 'application savvy' or who might have access to experienced educators or family members who could help them discern the intention of the questions" (p. 14). In effect, Childs and colleagues (2011) contend that explicit processes provide a more level playing field.

This consideration is not uniformly supported in the literature, however. Hirschkorn and Sears (2015) argue that explicit admission processes enable applicants to "tell us just what they think we want to read" (p. 451). Certainly this speaks to DeLuca's (2012) inclusivity dilemma: applicants are unlikely to admit if they are racist in their applications. Thus, research in admission practices remains divided on how best to connect designed purposes with actual practices. As Casey and Childs (2011) and Jacobowitz (1994) observe, this gap suggests a need for ongoing research to develop a clearer understanding of admissions practices as they relate to teacher education programs.

\section{Equity Issues in Admissions Practices}

Equity issues represent a significant concern in admissions practices. As Childs and Ferguson (2015) note, "the current teaching force does not reflect the diversity of the student population" (p. 428). Aboriginal students, for example, are consistently underrepresented at the postsecondary level and in the teaching population (Childs et al., 2011; Minister's National Working Group on Education, 2002). The Minister's National Working Group on Education noted that while "First Nations students will [soon] represent between $25 \%$ and $50 \%$ of the entire elementary student population in several provinces and territories" (p. 6), Aboriginal teachers represent only $1.3 \%$ of Canadian educators. While increasing ratios of representation will not solve all equity issues (Archibald, Pidgeon, Janvier, Commodore, \& McCormick, 2002), this lack of representation may contribute to shortfalls in Canadian education (Childs et al., 2011). 
Fortunately, some institutions are responding to these equity issues. The University of British Columbia, for example, gives specific consideration to First Nations applicants who do not meet the university's minimum grade requirements (Oloo, 2007). Similarly, Nickel and colleagues (2015) observe that applicants in Manitoba will be given specific consideration if they identify as a member of an underrepresented group, including visible minorities and persons with disabilities. Among those institutions who do articulate equity policies, however, specific responses are varied. DeLuca (2012) notes that some programs use self-identification forms to screen and select all applicants, while others only look to this data after applicants have been ranked. Thus, the presence of an equity policy in admissions does not necessarily mean that policy is consistent with practices in other institutions.

This variation in equity policies is sometimes problematic. As Thomson and colleagues (2011) observe, applicants tended to doubt institutions' claims about how self-identification forms would be used in the admissions process. Aboriginal applicants in particular may be concerned about racism and racial stereotyping in their applications (Oloo, 2007). Childs and colleagues (2011) also note that "applicants from underrepresented groups may have less access to information about admissions standards and processes and, if they do apply, may encounter prejudice concerning their ability to succeed in higher education" (p. 3). Further, as Archibald and colleagues (2002) explain, articulated goals do not always match how policies are enacted. Thus, it seems unsurprising that applicants may not perceive admissions processes as welcoming to members of underrepresented groups (Childs \& Ferguson, 2015). Given goals to improve equity access in teacher education (Villegas \& Irvine, 2010), these issues seem particularly relevant to institutions seeking to revise their admissions practices.

How, then, might teacher educators respond to equity issues in admissions? Caskey and colleagues (2001) suggest that "specific demands placed on applicants should be thought through; for example, the expense of extensive test programs may be an unfair barrier to less affluent applicants" (p. 11). That is, by considering how practices will affect actual applicants, programs may be able to reduce institutional barriers. Archibald and colleagues (2002) contend that teacher educators should seek to understand why applicants wish to enter the profession, and develop culturally sensitive relationships to better inform their equity policies. In a similar vein, 
the Minister's National Working Group on Education (2002) specifically recommends that institutions respect and promote indigenous ways of knowing. This is consistent with the Truth and Reconciliation Commission's (2015) recommendation that Aboriginal peoples themselves be intimately involved in bettering Aboriginal education at all levels.

These recommendations may speak to Oloo's (2007) concern that a lack of information about Aboriginal applicants' learning experiences serves as a barrier to equity in education. Archibald and colleagues (2002) connect these issues to specific policy recommendations. They suggest that institutions should consider including the following in their admissions requirements: “the individuals' previous experience, knowledge of First Nations cultures and traditions, connection to First Nations communities, and understanding and awareness of the needs and unique characteristics of First Nations students" (p. 17). As Oloo (2007) notes, however, changing admissions requirements cannot alone resolve equity issues in teacher education programs. Therefore, teacher educators may wish to consider other possibilities.

One such alternative to addressing equity issues involves rethinking how the admissions process itself is structured. For example, Kotzee and Martin (2013) note that some institutions apply a "levelling conception" (p. 626), where policies are enacted to provide equal opportunities to applicants from various backgrounds. Alternatively, they observe that other institutions use a "remedy conception" to enhance the admission opportunities for specific groups (Kotzee \& Martin, p. 626). Both of these responses are similar to Guinier's (2003) notion of sponsored mobility. In a sponsored mobility framework, teacher educators select a predetermined number of equity applicants based on supplementary factors and individual exceptions (Guinier, 2003). This discretion, however, can be problematic, as sponsored mobility is not always transparent, and may exist only as an addendum to an otherwise contest-based admissions policy (Childs et al., 2011; Guinier, 2003).

Given the limitations of contest and sponsored mobility policies, Guinier (2003) proposes another framework: structural mobility. Structural mobility reframes admissions practices by advocating that individual institutions admit students using processes that meet local needs (Guinier, 2003). To provide a specific example, Guinier (2003) cites sweeping changes to how 
Texas universities structure their admissions processes. Historically, "ten percent of the state's high schools - particularly those in affluent, predominantly white areas . . had been providing fifty percent to seventy-five percent of the freshman class" (Guinier, 2003, p. 19). That is, the state's traditional admissions process resulted in mostly rich, white students: an unrepresentative group. To address this issue, stakeholders from Texas' universities decided to instead admit "students in the top ten percent of every graduating high school class" (p. 19), thus reaching high-performing students in schools that would otherwise see limited representation at the university (Guinier, 2003). The author also notes that students admitted under this new framework achieved higher academic averages than students admitted through sponsored mobility systems. In addition to admitting a more diverse range of candidates, this reframing also makes the admissions process more explicit, addressing the ongoing concern of low transparency in equity admissions policies (Guinier, 2003; Childs et al., 2011). Thus, revisiting equity practices may also address other challenges in the admissions process.

\section{Assessment Tools in Admissions}

Regardless of what a program values or the purposes its admissions serve, every teacher education program must decide how those values will be assessed, and what tools will be used in the assessment process. As Casey and Childs (2011) note, different programs use different combinations of these tools to make their admissions decisions. How these tools are used, however, is not always made explicit (Smith \& Pratt, 1996). Further, stakeholders are often resistant to changing which admissions tools are used (Marrin et al., 2004). This resistance is caused, in part, by disagreements in the field and in the literature about how best to select teacher candidates (Caskey et al., 2001), and because determining which assessment tools are most effective is not a simple task (Marrin et al., 2004). As with other aspects of admissions practices, assessment tools are a complex part of teacher education policymaking.

Many studies and universities are interested in selecting the correct assessment tool to use in their programs (Caskey et al., 2001; Petrarca \& LeSage, 2014). Unfortunately, as Ackley, Fallon, and Brouwer (2007) discuss, assessment tools used by universities may not be valid, and may not actually select candidates who are most likely to succeed in the program or the profession. Further, while teacher educators value non-cognitive qualities and select tools to 
measure these qualities, assessment tools are often criticized for being unable to objectively assess applicants' non-cognitive abilities (Albanese et al., 2003; DeLuca, 2012; Thomas \& Kane, 2015). Challenges facing assessment tools include inconsistent inter-rater reliability (Thomson et al., 2011), as well as relying on individual assessment tools to provide information about an applicant's abilities (Ackley et al., 2007). To address reliability, Ackley and colleagues suggest providing rater training, while Caskey and colleagues advocate for rigorous third-rater systems when raters' scores vary significantly. Denner et al. (2001) suggest that applicants will perform differently in different contexts, and thus argue that "the ethical requirements of high-stakes assessment demand multiple sources of evidence" (p. 168). Given these concerns, the remainder of this section examines seven possible assessment tools that teacher educators might choose to use in their admissions processes.

\section{Academic Averages}

While academic averages are by far the most common tool for assessing program applicants, they are not a universally accepted measurement of applicant ability (Casey \& Childs, 2011). Byrnes, Kiger, and Shechtman (2003) contend that by emphasizing academic criteria, institutions overlook applicants" "verbal, interpersonal, and leadership qualities" (p. 163). Casey and Childs (2011) note that there is a relationship between applicants' academic averages and their success in teacher education programs, but caution that this relationship may be limited to the academic portions of these programs. Further, academic averages do not seem to serve as strong predictors of a candidate's performance once they enter the profession (Ackley et al., 2007; Smith \& Pratt, 1996). As a result, Smith and Pratt (1996) contend that academic averages should be used alongside other assessment tools such as those included in the remainder of this section.

\section{Standardized Tests and Letters of Reference}

Standardized tests and letters of reference are both completed outside of institutions' application processes, and are not used in Canadian teacher education as often as they are in other admissions contexts (Ackley et al., 2007). Like academic averages, standardized tests are intended to provide institutions with information about applicants' cognitive abilities. As Ackley and colleagues (2007) note, however, "there is little research that indicates a relationship 
between a score on a teacher examination, teaching performance, and student learning in the classroom" (p. 659). Further, Guinier (2003) contends that standardized tests favour applicants from privileged backgrounds. She notes that "the correlation between test scores and SES indicators is even stronger than the correlation between test scores and future academic performance" (Guinier, 2003, pp. 12-13). Letters of reference may be similarly problematic. While these letters are intended to attest to an applicant's abilities or qualities related to teaching, they may not be objective assessments (Casey \& Childs, 2007). Further, since applicants choose who to include as a reference, their contents may not be reliable or informative (Albanese et al., 2003). Teacher educators must therefore consider how much weight they assign to these tools if they are used in their admissions process.

\section{Written Statements}

After academic averages, written statements are the most commonly used tools in teacher education admissions. Denner and colleagues contend that written statements may provide additional information about applicants' dispositions as they relate to the program. Similarly, Hirschkorn and Sears (2015) suggest that sufficiently ambiguous application questions enable applicants to share their perspectives and beliefs, without revealing for what the admissions committee is looking. Further, Kosnik and colleagues (2005) argue that this tool allows them to select teacher candidates who possess the qualities necessary to succeed in the profession.

Written statements do, however, face a number of limitations. Albanese and colleagues (2003) observe that given the wide variation in types of personal statements, it is difficult to develop a standardized, valid way of comparing applicants' abilities. In a similar vein, since applicants write their statements over time without supervision, they may receive help from outside sources (Casey \& Childs, 2007; DeLuca, 2012). Finally, as with other assessment tools, ratings of written statements may not be accurate predictors of success in the practicum or in the broader profession (Ackley et al., 2007; Casey \& Childs, 2007). These challenges demonstrate why some teacher education programs are already reviewing how written statements are being used in their programs (DeLuca, 2012; Thomson et al., 2011). 


\section{Individual Interviews}

Despite their popularity, individual interviews are criticized for their low reliability, particularly those interviews which are less structured or which focus on past behaviour rather than situational responses (Blouin, 2010; Petrarca \& LeSage, 2014; Smith \& Pratt, 1996). While programs may develop highly structured protocols for their interviews, "the extent to which these protocols [are] implemented is unknown” (Petrarca \& LeSage, 2014, p. 258). Past studies examining inter-rater reliability in interviews have found correlations ranging from 0.14 to 0.96 (Albanese et al., 2003; Eva et al., 2004; Thomas et al., 2015). This wide variation in findings has prompted many admissions researchers to contend that using interviews as an admissions tool may be unfair or unethical (Blouin, 2010; Eva, et al., 2004; Kreiter et al., 2004). Implementing interviews is also an expensive process (Eva et al., 2004) that requires time commitments from multiple stakeholders (Casey \& Childs, 2007; Petrarca \& LeSage, 2014). In addition, because of the limited time for each applicant, interviews may not allow teacher educators to explore many issues in significant depth (Blouin, 2010). These limitations pose significant challenges for institutions seeking to use individual interviews in their admissions process.

\section{Multi-Applicant Tools}

Teacher educators interested in applicants' non-cognitive qualities may be interested in multi-applicant or group assessment tools. Caskey and colleagues (2001) contend that these tools have "strong face validity for admissions: [a] collaborative group task is much like the expectations of performance for program course work and field placements" (p. 19). That is, group assessments may reveal how applicants make decisions and participate in groups (Kosnik et al., 2005; Petrarca \& LeSage, 2014). Further, DeLuca (2012) observes that group interview ratings may be more reliable predictors of applicants' performance and success than academic averages. As Caskey and colleagues (2001) note, however, group assessments require extensive planning and preparation to implement effectively, and so teacher educators should consider these challenges before adopting this tool. One particular format that represents a recent, comprehensive effort to adapt group assessment tools is the multiple mini interview (or MMI). This medical education tool may warrant investigation for possible teacher education contexts (see Eva et al., 2004; Thomas et al., 2015). 


\section{Digital Assessment Tools}

Digital assessment tools are those which assess applicants' non-cognitive qualities through online real-time video and written responses to specific situations (Dore et al., 2009). Dore and colleagues (2009) found, in two studies examining the reliability and validity of one such tool, that the digital assessments correlated with more expensive assessment scores and featured strong inter-rater reliability (ranging 0.81-0.95). Tiller and colleagues (2013) similarly found that such digital assessments reduced costs by an estimated $84 \%$ as compared to a fully face-to-face admissions process. Thus, Dore and colleagues (2009) suggest that educators may be interested in using digital assessments for their own admissions processes. While these tools originate from a medical education context, teacher educators might use professional teaching organizations to ensure similar construct validity (Dore et al., 2009). Importantly, Dore and colleagues (2009) do caution that their findings are preliminary and have not yet established predictive validity for candidate performance. Thus, as with other tools outlined in this section, further research is needed.

\section{Final Words}

As is hopefully apparent, teacher educators should continue to reflect on how to align the purposes and philosophies of their admissions policies with actual practices (Kitchen \& Petrarca, 2016). Revising admissions practices necessarily involves a consideration of the contexts and challenges surrounding teacher education programs. This includes considerations of equity issues in admissions, as well as the research examining various admissions tools. Taken together, these considerations provide an overview of current research in teacher education admissions and will hopefully enable stakeholders to engage in more comprehensive reviews of their admissions practices.

\section{Acknowledgement}

This research was funded by a grant from the Department of Teacher Education of Brock University.

Michael Holden (M.Ed., B.Ed.) is a researcher for the Department of Teacher Education at Brock University and the Youth Leadership Facilitator for the Werklund School of Education at the University of Calgary. His research interests include examining the effects of educational policies and learning experiences on the development of new teachers, and working with teacher educators to improve academic and co-curricular programming. He served as the lead author of 
the province-wide study of admissions practices that this article is based on, and is currently collaborating with stakeholders from Ontario's teacher education programs to investigate equity and access in the province's four-semester teacher education programs.

Julian Kitchen is a professor in the Faculty at Brock University in St. Catharines, Ontario, Canada. His work in education extends to studying and supporting teachers and teacher educators. Dr. Kitchen is lead editor of Self-Study and Diversity II, Narrative Inquiries into Curriculum-making in Teacher Education and Canadian Perspectives on the Self-Study of Teacher Education Practices. He is lead author of Professionalism, Law and the Ontario Educator and was the editor of Brock Education, a peer-reviewed journal. Dr. Kitchen has been involved in several projects, including several funded by the Social Sciences and Humanities Research Council on Aboriginal education, as well as studies of queer issues in education. Dr. Kitchen was director of the Tecumseh Centre for Aboriginal Research and Education from 2013 to 2016.

\section{References}

Ackley, B. C., Fallon, M. A., \& Brouwer, N. (2007). Intake assessments for alternative teacher education: Moving from legitimation towards predictive validity. Assessment \& Evaluation in Higher Education, 32(6), 657-665.

Albanese, M. A., Snow, M. H., Skochelak, S. E., Huggett, K. N., \& Farrell, P. M. (2003). Assessing personal qualities in medical school admissions. Academic Medicine, 78, 313321.

Archibald, J., Pidgeon, M., Janvier, S., Commodore, H., \& McCormick, R. (2002). Teacher recruitment, retention and training: Implications for First Nations education: A literature review. Ottawa, ON: Minister's Working Group on Education, Indian and Northern Affairs.

Blouin, D. (2010). Reliability of a structured interview for admission to an emergency medicine residency program. Teaching and Learning in Medicine, 22(4), 246-250. doi: 10.1080/10401334.2010.511979

Byrnes, D. A., Kiger, G., \& Shechtman, Z. (2003). Evaluating the use of group interviews to select students into teacher education programs. Journal of Teacher Education, 54(2), 163-172.

Casey, C. E., \& Childs, R. A. (2007). Teacher education program admission criteria and what beginning teachers need to know to be successful teachers. Canadian Journal of Educational Administration and Policy, 67, 1-24.

Casey, C., \& Childs, R. (2011). Teacher education admission criteria as measure of preparedness for teaching. Canadian Journal of Education, 34(2), 3-20.

Caskey, M. M., Peterson, K. D., \& Temple, J. B. (2001). Complex admission selection procedures for a graduate preservice teacher education program. Teacher Education Quarterly, 28(4), 7-21.

Childs, R. A., Broad, K., Gallagher-Mackay, K., Sher, Y., Escayg, K., \& McGrath, C. (2011). Pursuing equity in and through teacher education program admissions. Education Policy Analysis Archives, 19(24). Retrieved from http:/epaa.asu.edu/ojs/article/view/803 
Childs, R., \& Ferguson, A. K. (2015). Changes in, to, and through the initial teacher education program admission process. In L. Thomas \& M. Hirschkorn (Eds.), Change and progress in Canadian teacher education: Research on recent innovations in teacher preparation in Canada (pp. 420-440). Ottawa, ON: Canadian Association for Teacher Education.

Childs, R. A., Ferguson, A. K., Herbert, M. B., Broad, K., \& Zhang, J. (2016). Evaluating admission criteria effects for under-represented groups. Higher Education Research \& Development, 1-11.

Crocker, R. \& Dibbon, D. (2008). Teacher education in Canada: A baseline study. H. Raham (Ed.). Kelowna, BC: Society for the Advancement of Excellence in Education.

DeLuca, C. (2012). Selecting inclusive teacher candidates; Validity and reliability issues in admission policy and practice. Teacher Education Quarterly, 39(4), 7-31.

Denner, P. R., Salzman, S. A., \& Newsome, J. D. (2001). Selecting the qualified: A standardsbased teacher education admission process. Journal of Personnel Evaluation in Education, 15(3), 165-180.

Dore, K. L., Reiter, H. I., Eva, K. W., Krueger, S., Scriven, E., Siu, E., Hilsden, S., Thomas, J., \& Norman, G. R. (2009). Extending the interview to all medical school candidates: Computer-based multiple sample evaluation of noncognitive skills (CMSENS). Academic Medicine, 84, 9-12.

Eva, K., Rosenfeld, J., Reiter, H. \& Norman, G. (2004). An admissions OSCE: The multiple mini-interview. Medical Education, 38, 314-326. doi:10.1046/j.1365-2923.2004.01776.x

Falkenberg, T. (2010). Admission to teacher education programs: The problem and two approaches to addressing it. Canadian Journal of Educational Administration and Policy, 107, 1-35.

Guinier, L. (2003). Admissions rituals as political acts: Guardians at the gates of our democratic ideals. Harvard Law Review, 117, 113-225.

Hirschkorn, M., \& Sears, A. (2015). More than gatekeeping: The pedagogical potential of admissions procedures for teacher education. In L. Thomas \& M. Hirschkorn (Eds.), Change and progress in Canadian teacher education: Research on recent innovations in teacher preparation in Canada (pp. 441-463). Ottawa, ON: Canadian Association for Teacher Education.

Holden, M., Kitchen, J., Petrarca, D., \& LeSage, A. (2016). Evolving practices: Admissions policies in Ontario teacher education programs. St. Catharines, ON: Brock University.

Jacobowitz, T. (1994). Admission to teacher education programs: Goodlad's sixth postulate. Journal of Teacher Education, 45(1), 46-52.

Kitchen, J. \& Petrarca, D. (2015). Teacher education in Ontario: On the cusp of change. In T. Falkenberg (Ed.), Handbook of Canadian teacher education research: Initial teacher education (pp. 62-76). Ottawa, ON: Canadian Association for Teacher Education.

Kitchen, J. \& Petrarca, D. (2016). Approaches to teacher education. In J. Loughran and M. L. Hamilton (Eds.), International handbook of teacher education research: Initial teacher education (pp. 137-186). Rotterdam, The Netherlands: Springer.

Kosnik, C., Brown, R., \& Beck, C. (2005). The preservice admissions process: What qualities do future teachers need and how can they be identified in applicants? The New Educator, 1, 101-123. doi: 10.1080/15476880590932210

Kotzee, B., \& Martin, C. (2013). Who should go to university? Justice in university admissions. Journal of Philosophy of Education, 47(4), 623-641. 
Kreiter, C. D., Yin, P., Solow, C., \& Brennan, R. L. (2004). Investigating the reliability of the medical school admissions interview. Advances in Health Sciences Education, 9, 147159.

Marrin, M. L., McIntosh, K. A., Keane, D., \& Schmuck, M. L. (2004). Use of the pairedcomparison technique to determine the most valued qualities of the McMaster medical programme admissions process. Advances in Health Sciences Education, 9, 129-135.

Minister's National Working Group on Education. (2002). Our children: Keepers of the sacred knowledge. Commissioned report by Minister of Indian and Northern Development Canada.

Mulholland, V., \& Salm, T. (2015). Looking backward to look forward: The story of interpreting program renewal through the internship seminar. In L. Thomas \& M. Hirschkorn (Eds.), Change and progress in Canadian teacher education: Research on recent innovations in teacher preparation in Canada (pp. 108-133). Ottawa, ON: Canadian Association for Teacher Education.

Nickel, J., O’Connor, K., \& Falkenberg, T. (2015). Initial teacher education in western Canada. In T. Falkenberg (Ed.), Handbook of Canadian research in initial teacher education (pp. 39-60). Ottawa, ON: Canadian Association for Teacher Education.

O’Connor, K., Nickel, J., \& Sterenberg, G. (2015). Revisiting the authority of experience in teacher education. In L. Thomas \& M. Hirschkorn (Eds.), Change and progress in Canadian teacher education: Research on recent innovations in teacher preparation in Canada (pp. 12-39). Ottawa, ON: Canadian Association for Teacher Education.

Oloo, J. A. (2007). Aboriginal university student success in British Columbia, Canada: Time for action. The Australian Journal of Indigenous Education, 36, 88-99.

Ontario Ministry of Education. (2013a). Giving new teachers the tools for success: Ontario enhancing teacher education, supporting greater student achievement. Retrieved from: http://news.ontario.ca/edu/en/2013/06/giving-new-teachers-the-tools-for-success.html

Ontario Ministry of Education. (2013b). Ontario regulation 283/13: Amending Ontario regulation 347-02. Retrieved from http://www.elaws.gov.on.ca/html/source/regs/english/2013/elaws_src_regs_r13283_e.htm

Petrarca, D. \& LeSage, A. (2014). Should it stay or should it go? Re-considering the pre-service teacher education admissions interview. In. S. Van Nuland (Ed.), Proceedings of International Conference on Education for Teaching World Assembly, 2014 (pp. 252 261). Oshawa, ON: University of Ontario Institute of Technology.

Smith, H. A., \& Pratt, D. (1996). The use of biodata in admissions to teacher education. Journal of Teacher Education, 47(1), 43-52.

Thomas, L., \& Kane, R. (2015). Reforms in teacher education in Quebec and Ontario: Restructuring vs reconceptualization. In L. Thomas \& M. Hirschkorn (Eds.), Change and progress in Canadian teacher education: Research on recent innovations in teacher preparation in Canada (pp. 158-188). Ottawa, ON: Canadian Association for Teacher Education.

Thomson, D., Cummings, E., Ferguson, A. K., Moizumi, E. M., Sher, Y., Wang, X., Broad, K., Childs, R. A. (2011). A role for research in initial teacher education admissions: A case study from one Canadian university. Canadian Journal of Educational Administration and Policy, 121, 1-23. 
Choosing How We Choose

Tiller, D. J., O’Mara, D., Rothnie, I., Dunn, S. M., Lee, L., \& Roberts, C. (2013). Internet-based multiple mini-interviews for candidate selection for graduate entry programs. Medical Education, 47(8), 801-810.

Villegas, A. M., \& Irvine, J. J. (2010). Diversifying the teaching force: An examination of major arguments. Urban Review 42, 175-192. 